Article

\title{
De Novo Transcriptome Assembly and Population Genetic Analyses for an Endangered Chinese Endemic Acer miaotaiense (Aceraceae)
}

\author{
Xiang $\mathrm{Li}^{1}{ }^{1}$, Meng Li ${ }^{1}$, Lu Hou ${ }^{1}$, Zhiyong Zhang ${ }^{2}$, Xiaoming Pang ${ }^{1}$ and Yingyue $\mathrm{Li}^{1}{ }^{1, *}$ \\ 1 National Engineering Laboratory for Tree Breeding, College of Biological Sciences and Technology, \\ Beijing Forestry University, Beijing 100083, China; 1x2016bjfu@163.com (X.L.); limeng@bjfu.edu.cn (M.L.); \\ houlu822@163.com (L.H.); xmpang@bjfu.edu.cn (X.P.) \\ 2 Beijing Key Laboratory of Ornamental Plants Germplasm Innovation and Molecular Breeding, \\ National Engineering Research Center for Floriculture, Beijing Laboratory of Urban and Rural Ecological \\ Environment, Key Laboratory of Genetics and Breeding in Forest Trees and Ornamental Plants of Ministry \\ of Education, School of Landscape Architecture, Beijing Forestry University, Beijing 100083, China; \\ zhangzhiyong543@163.com \\ * Correspondence: yingyueli@bjfu.edu.cn; Tel.: +86-01-6233-6817
}

Received: 13 June 2018; Accepted: 24 July 2018; Published: 27 July 2018

\begin{abstract}
Acer miaotaiense (P. C. Tsoong) is a rare and highly endangered plant in China. Because of the lack of genomic information and the limited number of available molecular markers, there are insufficient tools to determine the genetic diversity of this species. Here, 93,305 unigenes were obtained by multiple assembled contigs with a transcriptome sequencing program. Furthermore, 12,819 expressed sequence tag-derived simple sequence repeat (EST-SSR) markers were generated, 300 were randomly selected and synthesized, 19 primer pairs were identified as highly polymorphic (average number of alleles $\left(\mathrm{N}_{\mathrm{a}}\right)=8$, expected heterozygosity $\left(\mathrm{H}_{\mathrm{e}}\right)=0.635$, polymorphism information content $(\mathrm{PIC})=0.604$ ) and were further used for population genetic analysis. All 261 samples were grouped into two genetic clusters by UPGMA, a principal component analyses and a STRUCTURE analyses. A moderate level of genetic differentiation (genetic differentiation index $\left(\mathrm{F}_{\mathrm{st}}\right)=0.059-0.116$, gene flow $=1.904-3.993)$ among the populations and the major genetic variance $(81.01 \%)$ within populations were revealed by the AMOVA. Based on the results, scientific conservation strategies should be established using in situ and ex situ conservation strategies. The study provides useful genetic information for the protection of precious wild resources and for further research on the origin and evolution of this endangered plant and its related species.
\end{abstract}

Keywords: Acer miaotaiense; transcriptome sequencing; genetics diversity; population structure; conservation implication

\section{Introduction}

Acer miaotaiense (P. C. Tsoong), a perennial woody plant belonging to Acer (family Aceraceae), is an endangered species mainly distributed in the Gansu and Shaanxi Provinces of China [1,2]. A. miaotaiense was listed as a third-class nationally protected plant in the Chinese Red Data Book in 1992 [3] and was considered a vulnerable species in the International Union for the Conservation of Nature in 2004 [4]. Because of over-exploitation, the growth and breeding of A. miaotaiense are seriously threatened, and the outlook is not good. As a distinctive species among the Aceraceae family, A. miaotaiense has nearly horizontal fruit wings and, therefore, is of great significance in studies of the morphological evolution and classification of Aceraceae. Additionally, it is a popular landscaping tree [2], and its bark, leaves and fruit can be used as raw materials for tannin extraction, resulting 
in A. miaotaiense having a large economic and ornamental value. However, a high seed abortion rate, weak natural regeneration, strict habitat conditions and frequent human exploitation have significantly reduced the number of natural populations and narrowed the geographic distribution range of $A$. miaotaiense, which resulted in it being classified as an endangered plant [5].

Studies regarding A. miaotaiense were mainly concerned with raising seedlings, fruiting characteristics and reproductive biology [6-8], and only a few genetic studies focused on population genetics and protection biology $[9,10]$. To protect and utilize precious wild resources of endangered species, it is necessary to have adequate molecular techniques to evaluate germplasm and study population and conservation genetics. Molecular markers have been widely used in genetic diversity analyses, marker-assisted selection, genetic map construction and evolutionary studies in plants and animals [11-14]. Compared with other traditional DNA-based molecular markers, microsatellites simple sequence repeats (SSRs) are effective markers for studying population genetics because of their high information content, codominance and high polymorphism rate [15,16]. Currently, a large number of studies, including those on genetic diversity, population structure and protective biology, have used SSRs isolated based on next-generation sequencing in endangered plant species, such as Origanum compactum [17], Phellodendron amurense [18] and Centaurea borjae [19].

Because of a lack of available genomic information, it was difficult to develop ideal SSR markers and to evaluate the genetic diversity and evolution of endangered species at the genome level [20-22]. Transcriptome sequencing represents an alternative to whole-genome sequencing because it is more cost-effective and can target genomic regions for important traits through corresponding expressed sequence tag (EST) sequences, which can be selected to develop abundant EST-SSRs [23,24]. These transcriptome sequencing-based markers not only have the characteristics of a high polymorphism rate and codominance, but also directly reflect expression, which was determined to be relatively conservative [25]. Because on these advantages, EST-SSRs have been widely used in plants, including Pinus dabeshanensis [26], Ziziphus jujube [27], Paeonia suffruticosa [28] and Robinia pseudoacacia [29], to construct genetic linkage maps, study genetic diversity and population structure, and construct core collections [30]. Therefore, transcriptome sequencing is a more forceful method for developing microsatellite markers than whole-genome sequencing. However, only a circumscribed number of SSRs were verified in Aceraceae [31,32]. To comprehensively analyze the genetic diversity and population structure of $A$. miaotaiense in natural populations in China, developing SSR markers by transcriptome sequencing is a first step. This will aid in providing genetic protection for natural resources.

In this study, for the first time, we developed EST-SSRs based on transcriptome sequencing data. These were utilized in studying genetic diversity and population structure and in further implementing feasible production strategies for this rare and vulnerable species, A. miaotaiense. Here, 93,305 unigenes with an average of 668 base pairs (bp) and an N50 value of 1138 bp were identified. A total of 19 EST-SSRs with high polymorphism rates were selected to assess the genetic diversity among 261 A. miaotaiense individuals and the structures of their six natural populations in the Qinling Mountain areas of China. The diversity analyses and EST-SSR markers described in this study will contribute to the further studies on the protection and utilization of germplasm resources of A. miaotaiense.

\section{Materials and Methods}

\subsection{Plant Materials}

Based on our field investigation in August 2017, a total of 261 A. miaotaiense individuals representing six wild populations were collected in this study, which contains its main distribution regions in China (Table 1 and Figure 1). To select representative samples, all collected individuals from six populations were spaced at least $50 \mathrm{~m}$ apart. All of six populations were identified from five sampling locations from two different regions, including Shaanxi province and Gansu province in China. Population Xiaolongshan (XLS) and Maiji (MJ) contained samples from Gansu, China. The samples from Shaanxi province composed by three locations, which included four populations: 
Houzhenzi (HZZ), Yuduhe (YDH), Baimagou (BMG) and Tangyu (TY). The altitude of all populations ranged from $1260 \mathrm{~m}$ (BMG) to $1520 \mathrm{~m}$ (MJ), and the average altitude was $1430 \mathrm{~m}$ (Table 1). Depending on geographical location, these sampled populations were further divided into three groups (G1, G2 and G3), respectively. The West of Qinling Mountains (G1) group consisted of XLS and MJ. North of the midland of the Qinling Mountains group (G3) contained TY. South of the midland of the Qinling Mountains group (G2) included HZZ, YDH and BMG (Figure 1). At the same time, the important phenotype characteristics (leaf length, leaf width and fruit shape) of all individuals was recorded.

Table 1. Summary of $A$. miaotaiense sampling locations in China.

\begin{tabular}{cccccc}
\hline Regions & Sampling Locality & Sample Size & Population Codes & Latitude (N)/Longitude (E) & Altitude (m) \\
\hline \multirow{2}{*}{ G1 } & Tianshui, Gansu & 149 & XLS & N: $34^{\circ} 18.405^{\prime} / \mathrm{E}: 106^{\circ} 08.323^{\prime}$ & 1504 \\
& Maiji, Gansu & 17 & MJ & N: $34^{\circ} 07.052^{\prime} / \mathrm{E}^{\circ} 105^{\circ} 54.214^{\prime}$ & 1520 \\
\hline \multirow{2}{*}{ G2 } & Zhouzhi, Shaanxi & 37 & HZZ & N: $33^{\circ} 50.680^{\prime} / \mathrm{E}: 107^{\circ} 48.068^{\prime}$ & 1502 \\
& Zhouzhi, Shaanxi & 29 & YDH & N: $34^{\circ} 50.057^{\prime} / \mathrm{E}: 107^{\circ} 47.395^{\prime}$ & 1500 \\
& Foping, Shaanxi & 22 & BMG $33^{\circ} 33.382^{\prime} / \mathrm{E}: 107^{\circ} 48.699^{\prime}$ & 1260 \\
\hline \multirow{2}{*}{ G3 } & Lantian, Shaanxi & 7 & TY & N: $34^{\circ} 02.577^{\prime} / \mathrm{E}: 107^{\circ} 53.075^{\prime}$ & 1293 \\
\hline
\end{tabular}

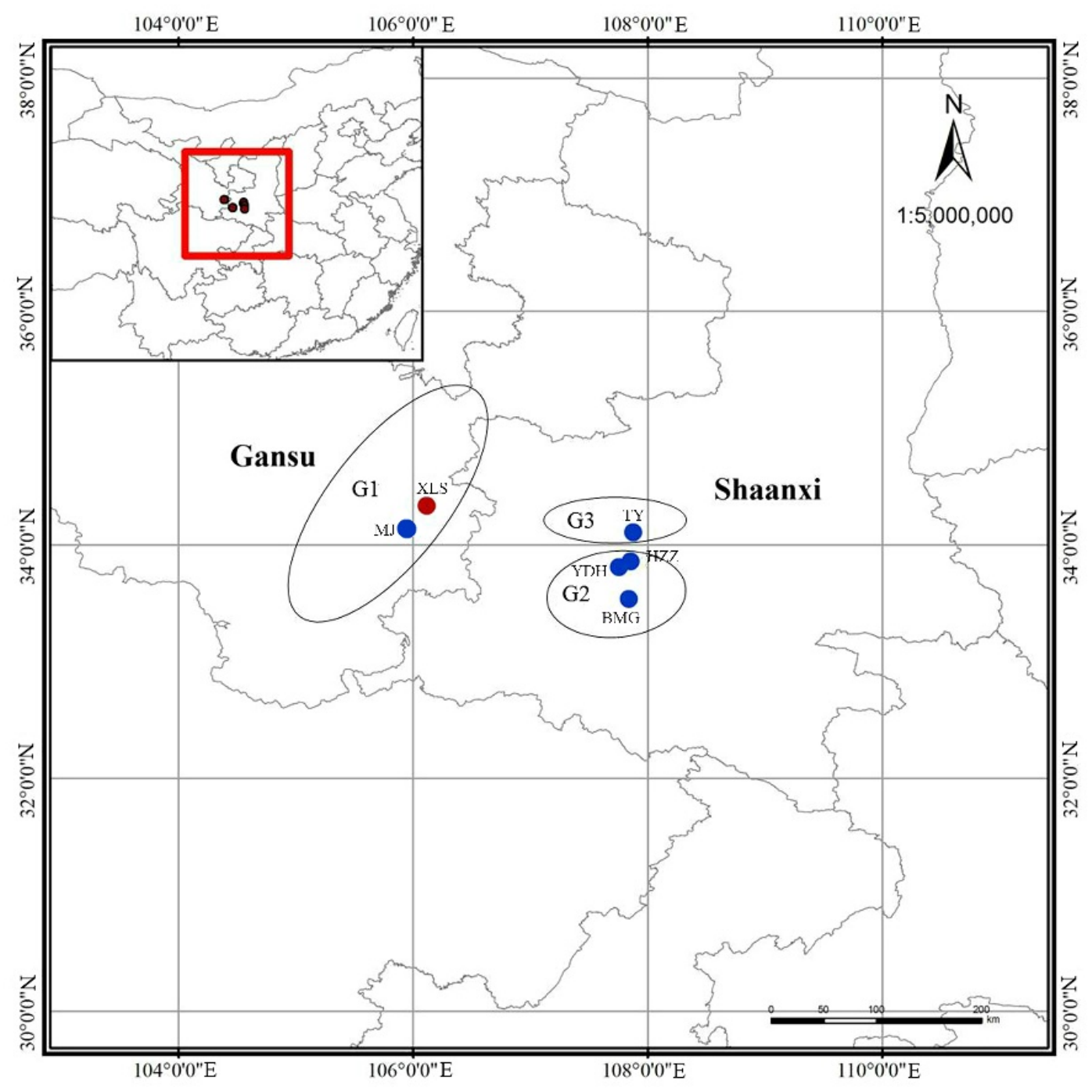

Figure 1. Geographic distribution of Acer miaotaiense collected in Qinling Mountains, China. Red dots represent genetic cluster $\mathrm{C} 1$, blue dots represent genetic cluster $\mathrm{C} 2$. 


\subsection{RNA Extraction, Library Preparation, Sequencing and De Novo Assembly}

Three fresh tissues (leaves, fruits and phloem) were frozen and stored instantly in liquid nitrogen prior to RNA extraction. Total RNA was isolated from all the tissues collected above using the method described by Ghawana et al. [33] and was detected using NanoDrop 2000 (Thermo Fisher Scientific, Wilmington, DE, USA) and the RNA Nano 6000 Assay Kit of the Agilent Bioanalyzer 2100 system (Agilent Technologies, Palo Alto, CA, USA). The RNA of three tissues are mixed to build sequencing libraries with three biological duplications. Sequencing libraries were constructed using NEBNext ${ }^{\circledR}$ Ultra ${ }^{\text {TM }}$ RNA Library Prep Kit for Illumina ${ }^{\circledR}$ (New England Biolabs, Ipswich, MA, USA). Briefly, purified mRNA was obtained from total RNA $(1 \mu \mathrm{g})$ per sample using poly-T oligo-attached magnetic beads; then, the mRNA was fragmented using divalent cations under elevated temperature in NEBNext First Strand Synthesis Reaction Buffer (5X). First, strand cDNA was produced based on the random hexamer primer and M-MuLV Reverse Transcriptase. Immediately after, a second strand cDNA was synthesized using DNA polymerase I and RNase H. After adenylation reaction of $3^{\prime}$ ends of DNA fragments, NEBNext Adaptor containing hairpin loop structure were ligated for hybridization. The fragments in library were purified with AMPure XP system (Beckman Coulter, Danvers, MA, USA) to firstly select for $240 \mathrm{bp}$ cDNA fragments; $3 \mu \mathrm{L}$ USER Enzyme (New England Biolabs) was incubated with size-selected, adaptor-ligated cDNA for $15 \mathrm{~min}$ at $37^{\circ} \mathrm{C}$ and then $5 \mathrm{~min}$ at $95^{\circ} \mathrm{C}$. Then PCR reaction was performed using Phusion High-Fidelity DNA polymerase, Universal PCR primers and Index $(X)$ Primer. Finally, PCR products were purified by AMPure XP system and the Agilent Bioanalyzer 2100 system was used to assess sequencing library quality and the clusters were sequenced on an Illumina Hiseq 2000 platform and paired-end reads were generated. Sequenced raw data described in this study were uploaded in the Sequence Read Archive (SRA) public database of the NCBI (No. SRR7195583).

Before assembly, the raw paired-end reads were firstly used to obtain high-quality clean reads. In addition, the Q20, Q30, GC-content and sequence duplication level of the clean data were calculated. Afterwards, transcriptome assembly was implemented using Trinity [34] and the min_kmer_cov was set to 2 (other parameters were set as default). The RNA library preparation and de novo assembly and further deep analyses were performed by Biomarker Technologies Co., Ltd. (Beijing, China).

\subsection{Sequence Annotation and Classification}

For functional annotation of the assembled unigenes, these sequences were aligned to the public databases by BLASTX program $\left(E\right.$-value $\left.<1.00 \times 10^{-5}\right)$, including $\mathrm{Nr}(\mathrm{NCBI}$ non-redundant protein sequences database); Pfam (Protein family database); KOG (eukaryotic orthologous groups); COG (Clusters of Orthologous Groups); Swiss-Prot (Swiss Institute of Bioinformatics databases); eggNOG (Evolutionary genealogy of genes: Non-supervised Orthologous Groups); KEGG (Kyoto Encyclopedia of Genes and Genomes databases); The representative GO (Gene Ontology) annotation was performed by the software Blast2GO [35].

\subsection{Simple Sequence Repeat Loci Identification and Primer Design}

The transcriptomes were analyzed using the MIcroSAtellite identification tool (MISA) (http:/ / pgrc.ipk-gatersleben.de/misa/misa.html) for identifying SSRs with a minimum of ten repeats for di-nucleotide motifs, five repeats for tri- and tetra-, four repeats for penta- and hexa-nucleotide motifs. The primer for each SSR locus was designed using Primer3 version 0.4.0 (http:// primer3. sourceforge.net/releases.php). The criteria for designing primers were as follows: primer length of 18-24 nucleotides; GC content of 40-60\%; annealing temperature between 55 and $60{ }^{\circ} \mathrm{C}$ with $55^{\circ} \mathrm{C}$ as optimum; PCR product size range of 100 to $350 \mathrm{bp}$. 


\subsection{DNA Isolation, PCR Amplification and Simple Sequence Repeats Validation}

Total genomic DNA was extracted from 261 individuals from silica-dried leaves using the Plant Genomic DNA Kit (TianGen Biotech, Beijing, China) and was used to check DNA integrity and purity using 1\% agarose gel electrophoresis and NanoDrop 2000 (Thermo Fisher Scientific). PCR amplification of each locus was implemented as shown by [36]. In addition, 300 primer pair sequences containing SSRs were randomly selected and were successfully screened in 16 individuals randomly selected among six populations for development and assessment of the polymorphism EST-SSR. Primers were synthesized by Sangon Biotech (Shanghai, China). To validate the SSR locus, the universal M13 sequence labeled by four fluorescent dyes (ROX, HEX, FAM and TAMRA) was added at the $5^{\prime}$ end of all forward primers.

\subsection{Statistical Analyses}

GeneMarker (version 1.5) [37] was used to obtain and analyze the microsatellite raw data obtained by the high performance capillary electrophoresis (HPCE). The genetic parameters of polymorphic loci were calculated by the GenAlEx software (version 6.5) [38], including observed heterozygosity $\left(\mathrm{H}_{\mathrm{o}}\right)$, $\mathrm{H}_{\mathrm{e}}, \mathrm{N}_{\mathrm{a}}$, effective number of alleles $\left(\mathrm{N}_{\mathrm{e}}\right)$, $\mathrm{F}_{\mathrm{st}}$, inbreeding coefficient $(\mathrm{F})$, Hardy-Weinberg equilibrium (HWE) and number of rare alleles (NRA). The gene flow $\left(\mathrm{N}_{\mathrm{m}}\right)$ was calculated as $\mathrm{N}_{\mathrm{m}}=\left(1-\mathrm{F}_{\mathrm{st}}\right) / 4 \times \mathrm{F}_{\mathrm{st}}$ based on the $\mathrm{F}_{\mathrm{st}}$ values. The PIC values of each SSR primer were obtained using the PIC calculation (PICcalc) progress [39]. To obtain the genetic variation of populations-including within populations, among populations, within groups and among groups-analyses of molecular variance (AMOVA) function of GeneAlEx version 6.5 was performed.

The Bayesian clustering analysis was implemented to evaluate the population genetic structure of A. miaotaiense populations using STRUCTURE version 2.3 [40]. Models were tested for K-values (testing from $\mathrm{K}=1$ to $\mathrm{K}=10$ ), and each independent run was performed by a burn-in period of 100,000 iterations and 100,000 Markov chain Monte Carlo repetitions. The K for the number of populations was assessed using the delta-K method by Structure Harvester program [41]. In addition, Nei's genetic distance [42] was calculated and used to construct an unweighted pair-group method with arithmetic averaging (UPGMA) phylogenetic tree using the PowerMarker program [43]. In order to obtain more intuitionistic genetic classification, interactive Tree Of Life (iTOL) [44] was further employed to make the display, manipulation and annotation of phylogenetic trees. The principal component analyses (PCA) was calculated and performed using the GenAlEx version 6.5 program.

Based on the longitude and latitude recorded by a global positioning system (GPS), the geographic distribution of the six populations was identified by the ArcGIS version 10.2 software (ESRI, Redlands, CA, USA). The geographic distance among the sampled locations was calculated by the Geographic Distance Matrix Generator (GDMG) version 1.2.3 software (http: / biodiversityinformatics.amnh.org/ opensource/gdmg/index.php) (AMNH, New York, NY, USA). The relative migration networks among the six populations was performed using the function 'divMigrates' [45] from 'diveRsity' package [46] in $\mathrm{R}$ (version 3.5.0) [47].

\section{Results}

\subsection{Sequencing, De Novo Assembly and Functional Annotation of Unigenes}

To comprehensively overview the transcriptome information, total RNA samples from three different tissues of an adult $A$. miaotaiense tree were used to sequence and generate a de novo assembly. A total of 21,812,509 raw sequencing reads were generated on the Illumina sequencing platform (Table S1). After data filtering to remove low-quality sequences, 21,485,322 high-quality clean reads were obtained with an $88.82 \%$ Q30 and a $44.46 \%$ GC content. Using Trinity software, the assembly of these high-quality reads generated 93,305 unigenes with paired-end reads, and the total length of the unigenes was $62,398,390 \mathrm{bp}$, with an average length of $668 \mathrm{bp}$ and an N50 value of $1138 \mathrm{bp}$ (Table S2). 
All of the A. miaotaiense unigenes were annotated into eight public databases. For the gene ontology (GO) functional classification, 24,267 unigenes ( $45.32 \%$ of the assembled unigenes) were assigned, and these terms could be divided into three categories: molecular function $(15,687,64.65 \%)$; biological process (4580, 18.87\%); and cellular component (4000, 16.48\%) (Figure 2). Moreover, 27,887 unigenes (52.08\%) were assigned KOG functional annotations and grouped into 26 functional categories (Figure S1). Among these categories, the group "General function prediction only" (5558, $19.93 \%$ ) was dominant, followed by "posttranslational modification, protein turnover, chaperones" (2521, 9.04\%) and "translation, ribosomal structure and biogenesis" (2510, 9.00\%). Among the 93,305 A. miaotaiense unigenes, 52,023 (55.76\%) were annotated to known proteins in the Nr database, with Citrus sinensis having the top known hits $(9496,18.25 \%)$, while unknown species represented $53.36 \%$ $(27,757)$ (Figure S2). The analyses of the KEGG pathways based on assembled unigenes revealed that 19,473 (20.87\%) were annotated and contained 131 biological pathways. Of these pathways, the ribosome (ko03010, 1677 unigenes, 7.89\%) had the highest number of unigenes among the genetic information processing categories, followed by carbon metabolism (ko01200, 1185, 5.58\%) and biosynthesis of amino acids (ko01230, 858, 4.04\%) among the metabolism categories (Table S3).

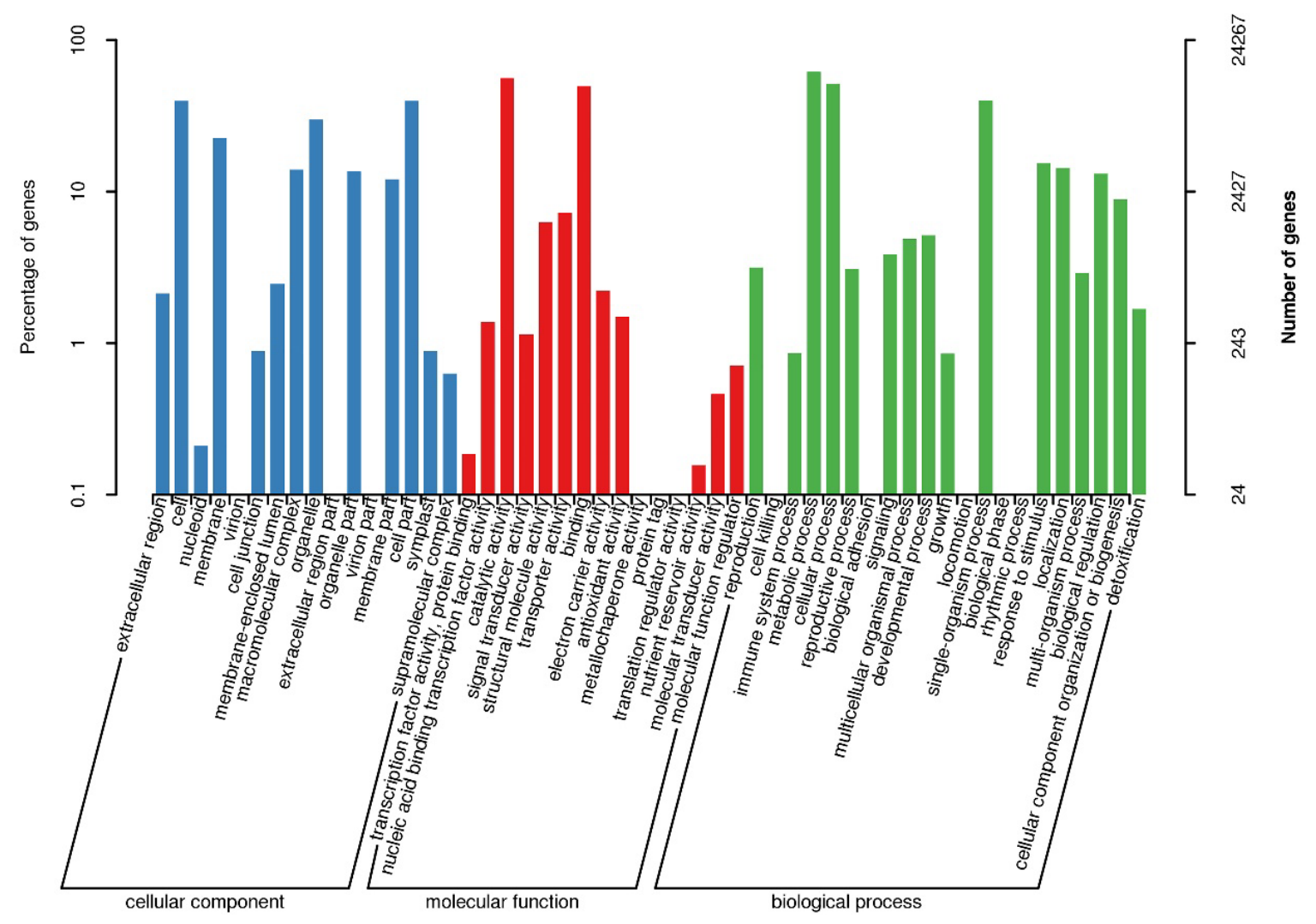

Figure 2. Functional classification of the assembled unigenes of A. miaotaiense based on gene ontology (GO) categories.

\subsection{Frequency and Distribution of Simple Sequence Repeats}

Table S4 presents the 12,765 potential EST-SSRs that were identified in $8655(9.28 \%)$ unigenes, of which 3049 sequences contained more than one EST-SSR locus and 1587 SSRs were present in compound formation. The average microsatellite density of the A. miaotaiense transcriptome was one per $4888 \mathrm{bp}$. The mono-nucleotide was the most common type of repeat $(5814,52.01 \%)$, followed by di-nucleotide $(2763,24.72 \%)$, tri-nucleotide $(2362,21.13 \%)$, tetra-nucleotide $(170,1.52 \%)$, penta-nucleotide $(45,0.40 \%)$ and hexa-nucleotide $(24,0.21 \%)$ repeats. In addition, the lowest number of repeat motifs per locus was five, with 10 tandem repeats of the EST-SSR $(1980,17.71 \%)$ being the most 
common. This was followed by six $(1310,11.72 \%), 5(1297,11.60 \%)$ and $11(1165,10.42 \%)$ repeats. The other numbers of the tandem repeats each accounted for $<10 \%$ of the EST-SSRs (Table S5). The most dominant type was A/T (5803; 51.91\%), followed by AG/CT (836, 7.48\%), GA/TC (689, 6.16\%), AT/AT $(619,5.54 \%)$, TA/TA $(431,3.86 \%)$, GAA/TTC $(238,2.13 \%)$, AGA/TCT $(201,1.80 \%)$ and AAG/CTT $(158,1.41 \%)$. Thus, the AG/CT and GAA/TTC repeats were the most abundant di- and tri-nucleotide motifs, respectively, in A. miaotaiense (Table S6).

\subsection{Development and Polymorphism Rates of New Expressed Sequence Tag-Derived Simple Sequence Repeats Markers}

In this study, 300 primer pair sequences containing SSRs were randomly selected from 1213 primer pairs designed by Primer3. We removed mono-nucleotide repeats from our analyses. Of the 300 selected primer pairs, 96 successfully PCR-amplified A. miaotaiense genomic DNA (Table S7), producing products of the expected size. The remaining primer pairs failed to generate the expected PCR products. All 96 successful primer pairs were used in 16 A. miaotaiense individuals to validate the polymorphisms by capillary electrophoresis. Of these, 19 primer pairs were highly polymorphic, and the remaining primer pairs were identified as monomorphic (Table 2). In total, 152 alleles were detected across the collected individuals, with a mean value of eight observed alleles per locus. The number of alleles varied from three (BFAM-107 and BFAM-254)) to 19 (BFAM-166). Among the 19 microsatellites, 35 of 152 rare alleles were found at 19 loci, with an average of 1842 . In addition, the PIC values for all of the loci ranged from 0.147 (BFAM-254) to 0.820 (BFAM-219), with an average of 0.604, and 14 of 19 loci had highly informative scores (PIC > 0.50) (Table 2).

\subsection{Genetic Diversity and Differentiation}

The genetic diversity levels of the six A. miaotaiense populations were estimated in Table 3. The highest level of genetic diversity occurred in XLS $\left(\mathrm{N}_{\mathrm{a}}=6.053, \mathrm{~N}_{\mathrm{e}}=2.965, \mathrm{H}_{\mathrm{o}}=0.512\right.$ and $\left.\mathrm{H}_{\mathrm{e}}=0.573\right)$, while the lowest diversity levels were in BMG $\left(\mathrm{N}_{\mathrm{e}}=2.561, \mathrm{H}_{\mathrm{o}}=0.464\right.$ and $\left.\mathrm{H}_{\mathrm{e}}=0.504\right)$ and TY $\left(\mathrm{N}_{\mathrm{e}}=3.173, \mathrm{H}_{\mathrm{o}}=0.496\right.$ and $\left.\mathrm{H}_{\mathrm{e}}=0.585\right)$. The fixation index $(\mathrm{F})$ values of the six populations varied from -0.046 to 0.147 , with a positive average, which indicated that the heterozygote is deficient, the homozygote is excessive and significant inbreeding occurred in the A. miaotaiense populations (Table 3).

Genetic distances and pairwise $\mathrm{F}_{\mathrm{st}}$ values calculated between populations are listed in Table 4, and they ranged from 0.173 to 0.401 and from 0.059 to 0.116 , respectively. The highest genetic distance value (0.401) was observed between MJ and BMG populations, while the lowest genetic distance value (0.173) was observed between XLS and TY populations. The pairwise $\mathrm{F}_{\text {st }}$ values and the genetic distances corresponded. The greatest level of differentiation occurred between MJ and BMG populations, while the lowest level of differentiation occurred between MJ and HZZ populations (Table 4). In this study, the AMOVA analyses revealed $81.01 \%$ genetic variance within populations, which indicated a high genetic diversity level within populations (Table 5). However, the variance component among populations (18.99\%) was lower than that within populations. In groups divided based on their geographical distribution, a lower genetic differentiation level (1.44\%) among the three groups was detected by AMOVA (Table 5). The relative migration networks among the six populations were estimated by divMigrate (Figure 3). A high level of gene flow was observed in the XLS population (from Gansu Province), while the other five populations grouped together exhibited a relatively low gene flow. The lowest gene flow value was 1.905, which was observed between the MJ and BMG populations, while the highest was 3.987, which was observed between the MJ and HZZ populations (Table S8). 
Table 2. Characterization of 19 polymorphic simple sequence repeats (SSRs).

\begin{tabular}{|c|c|c|c|c|c|c|c|c|c|c|}
\hline & Primer Sequences $\left(5^{\prime} \mathrm{ds}-3^{\prime}\right)$ & Repeat Motif & $\mathrm{Ta}\left({ }^{\circ} \mathrm{C}\right)$ & Expected Size (bp) & $\mathbf{N}_{\mathrm{a}}$ & $\mathrm{H}_{\mathrm{o}}$ & $\mathrm{H}_{\mathrm{e}}$ & PIC & HWE & NRA \\
\hline BFAM-2 & $\begin{array}{l}\text { F:AGGAGATGGAAAGCAGGGAT } \\
\text { R:GGGACTTTCGGACAAACAAA }\end{array}$ & $(\mathrm{CT})_{17}$ & 60 & 224 & 10 & 0.449 & 0.777 & 0.752 & $* * *$ & 1 \\
\hline BFAM-74 & $\begin{array}{l}\text { F:CTAAGACACCGTGCAAGCAA } \\
\text { R:ACGCATGATAGGGCTCGTAA }\end{array}$ & $(\mathrm{AT})_{8}$ & 60 & 196 & 9 & 0.591 & 0.779 & 0.747 & $* * *$ & 3 \\
\hline BFAM-50 & $\begin{array}{l}\text { F:TCTCCATCTCCCCTTGGTAA } \\
\text { R:GGAGGTTTCATGGACACGAT }\end{array}$ & $(\mathrm{TA})_{10}$ & 60 & 269 & 8 & 0.397 & 0.800 & 0.772 & $* * *$ & 2 \\
\hline BFAM-88 & $\begin{array}{l}\text { F:GAACTCCTTGTCGGATTCCA } \\
\text { R:ATTTCCACGGACCGTACTCA }\end{array}$ & $(\mathrm{TCT})_{8}$ & 60 & 243 & 5 & 0.289 & 0.35 & 0.329 & $* * *$ & 0 \\
\hline BFAM-34 & $\begin{array}{l}\text { F:GCGGTGATGAACTGATGATG } \\
\text { R:CACCCAAATCACCTTCGTCT }\end{array}$ & $(\mathrm{GA})_{7}$ & 60 & 140 & 6 & 0.506 & 0.566 & 0.517 & * & 3 \\
\hline BFAM-109 & $\begin{array}{l}\text { F:GTCATCACATGCCTTTCCCT } \\
\text { R:GCAACTCGGCTAAAGATTGC }\end{array}$ & $(\mathrm{GAT})_{8}$ & 60 & 244 & 4 & 0.238 & 0.238 & 0.223 & $* * *$ & 1 \\
\hline BFAM-91 & $\begin{array}{l}\text { F:TGACTTGTCCCTCAAATCCA } \\
\text { R:GAAAATGGGGTGTCTCCAAA }\end{array}$ & $(\mathrm{AT})_{13}$ & 60 & 206 & 10 & 0.753 & 0.82 & 0.796 & $* * *$ & 2 \\
\hline BFAM-219 & $\begin{array}{l}\text { F:AGAGTGCAAAGCAGCAAATG } \\
\text { R:CGTTGGGACTCATGTCAATG }\end{array}$ & $(\mathrm{AT})_{12}$ & 60 & 235 & 8 & 0.813 & 0.841 & 0.820 & $* * *$ & 1 \\
\hline BFAM-241 & $\begin{array}{l}\text { F:ATCAGAGAGGCGGACTTGAA } \\
\text { R:TCATTTGCCCTCCTAATTGC }\end{array}$ & (CAA)8 & 60 & 153 & 8 & 0.708 & 0.735 & 0.699 & $* *$ & 2 \\
\hline BFAM-254 & $\begin{array}{l}\text { F:GGACGAATGGAGATTGGAGA } \\
\text { R:AAAGAGCTCCAAGAGGGTGA }\end{array}$ & $(\mathrm{AAG})_{7}$ & 59 & 244 & 3 & 0.076 & 0.153 & 0.147 & $* * *$ & 0 \\
\hline BFAM-255 & $\begin{array}{l}\text { F:CGCACCTTTCAGTAATGCCT } \\
\text { R:AGAACATGCCCACAACCTGT }\end{array}$ & $(\mathrm{AT})_{10}$ & 60 & 264 & 13 & 0.882 & 0.822 & 0.801 & $* * *$ & 2 \\
\hline BFAM-136 & $\begin{array}{l}\text { F:GTGGGGAAATGAAGGGAAAT } \\
\text { R:GCATCTGTCCCGAATCAAAT }\end{array}$ & $(\mathrm{TTC})_{7}$ & 60 & 273 & 4 & 0.455 & 0.448 & 0.372 & $* * *$ & 0 \\
\hline BFAM-123 & $\begin{array}{l}\text { F:AGGCAGGTGTCAGTGTTTCA } \\
\text { R:GCCAGGTGGGTTCTACAAAA }\end{array}$ & $(\mathrm{GAA})_{10}$ & 60 & 208 & 8 & 0.564 & 0.675 & 0.621 & $* * *$ & 3 \\
\hline
\end{tabular}


Table 2. Cont.

\begin{tabular}{|c|c|c|c|c|c|c|c|c|c|c|}
\hline & Primer Sequences $\left(5^{\prime} \mathrm{ds}-3^{\prime}\right)$ & Repeat Motif & $\mathrm{Ta}\left({ }^{\circ} \mathrm{C}\right)$ & Expected Size (bp) & $\mathbf{N}_{\mathbf{a}}$ & $\mathbf{H}_{\mathbf{o}}$ & $\mathbf{H}_{\mathbf{e}}$ & PIC & HWE & NRA \\
\hline BFAM-262 & $\begin{array}{l}\text { F:TGTTGTGTTCGTTCCATCGT } \\
\text { R:CCTTTGGTTCCCTGACCTTT }\end{array}$ & $(\mathrm{AT})_{7}$ & 60 & 243 & 9 & 0.571 & 0.777 & 0.745 & $* * *$ & 3 \\
\hline BFAM-166 & $\begin{array}{l}\text { F:CAAATCCCGACAATCTCTCC } \\
\text { R:TGGAGGAAGCAGTCAAGGTT }\end{array}$ & $(\mathrm{CT})_{10}$ & 60 & 225 & 19 & 0.698 & 0.812 & 0.791 & $* * *$ & 6 \\
\hline BFAM-263 & $\begin{array}{l}\text { F:TATGGGCAGTCTTGGGTTTC } \\
\text { R:CCAGGAACAAGCATGGATTT }\end{array}$ & $(\mathrm{TG})_{10}$ & 60 & 223 & 13 & 0.523 & 0.774 & 0.743 & $* * *$ & 4 \\
\hline BFAM-178 & $\begin{array}{l}\text { F:ACCAAACCAGAGATCCAACG } \\
\text { R:AATCTCTCACGCCCCTTTCT }\end{array}$ & $(\mathrm{GA})_{11}$ & 60 & 176 & 5 & 0.667 & 0.675 & 0.631 & $* *$ & 1 \\
\hline BFAM-220 & $\begin{array}{l}\text { F:GCTCAACCATCCAACGATTT } \\
\text { R:TCCAGTGGCATCAGATTGAA }\end{array}$ & $(\mathrm{TA})_{13}$ & 60 & 273 & 7 & 0.620 & 0.775 & 0.740 & $* * *$ & 1 \\
\hline Total & & & & & 152 & 10.04 & 12.06 & 11.47 & & 35 \\
\hline Mean & & & & & 8 & 0.528 & 0.635 & 0.604 & & 1.842 \\
\hline
\end{tabular}

$\mathrm{N}_{\mathrm{a}}$, number of different alleles; $\mathrm{H}_{\mathrm{o}}$, observed heterozygosity; $\mathrm{H}_{\mathrm{e}}$, expected heterozygosity; HWE, deviation from Hardy-Weinberg equilibrium; PIC, polymorphic information content; $\mathrm{N}_{\mathrm{m}}$, number of effective migrants; NRA, number private allele; $\mathrm{ns}$, not significant; ${ }^{*} p<0.05$; ${ }^{* *} p<0.01 ; * * * p<0.001$. 
Table 3. Genetic diversity assessment of six populations based on 19 expressed sequence tag-derived simple sequence repeat (EST-SSRs).

\begin{tabular}{cccccccc}
\hline & Sample Size & $\mathbf{N}_{\mathbf{a}}$ & $\mathbf{N}_{\mathbf{e}}$ & $\mathbf{H}_{\mathbf{o}}$ & $\mathbf{H}_{\mathbf{e}}$ & $\mathbf{F}$ & Private Alleles \\
\hline XLS & 149 & 6.053 & 2.965 & 0.512 & 0.573 & 0.088 & 13 \\
MJ & 17 & 4.263 & 2.783 & 0.586 & 0.561 & -0.046 & 2 \\
HZZ & 37 & 5.737 & 3.249 & 0.55 & 0.602 & 0.106 & 9 \\
YDH & 29 & 4.211 & 2.755 & 0.584 & 0.557 & -0.046 & 3 \\
BMG & 22 & 4.053 & 2.561 & 0.464 & 0.504 & 0.056 & 6 \\
TY & 7 & 4.105 & 3.173 & 0.496 & 0.585 & 0.147 & 2 \\
Mean & 44 & 4.737 & 2.914 & 0.532 & 0.564 & 0.051 & 5.833 \\
\hline
\end{tabular}

Table 4. Nei's genetic distance (below asterisks) and pairwise genetic differentiation index $\left(\mathrm{F}_{\mathrm{st}}\right)$ (above asterisks) among six populations.

\begin{tabular}{ccccccc}
\hline & XLS & MJ & HZZ & YDH & BMG & TY \\
\hline XLS & $* * * *$ & 0.065 & 0.074 & 0.089 & 0.078 & 0.065 \\
MJ & 0.181 & $* * * *$ & 0.059 & 0.095 & 0.116 & 0.093 \\
HZZ & 0.251 & 0.218 & $* * * *$ & 0.082 & 0.083 & 0.077 \\
YDH & 0.293 & 0.325 & 0.291 & $* * * *$ & 0.103 & 0.091 \\
BMG & 0.227 & 0.401 & 0.267 & 0.313 & $* * * *$ & 0.096 \\
TY & 0.173 & 0.334 & 0.286 & 0.304 & 0.327 & $* * * *$ \\
\hline
\end{tabular}

Table 5. Analyses of molecular variance (AMOVA) for different populations and groups of A. miaotaiense.

\begin{tabular}{cccccc}
\hline & $\begin{array}{c}\text { Degrees of } \\
\text { Freedom }\end{array}$ & $\begin{array}{c}\text { Sum of } \\
\text { Squares }\end{array}$ & $\begin{array}{c}\text { Variance } \\
\text { Components }\end{array}$ & $\begin{array}{c}\text { Percentage of } \\
\text { Variation (\%) }\end{array}$ & $\begin{array}{c}\text { Genetic } \\
\text { Differentiation Index }\end{array}$ \\
\hline $\begin{array}{c}\text { Variance partition a } \\
\text { Among populations }\end{array}$ & 5 & 633.767 & 3.414 & 18.99 & $\mathrm{~F}_{\mathrm{st}}=0.190$ \\
Within populations & 255 & 3712.486 & 14.559 & 81.01 & \\
$\quad \begin{array}{c}\text { Total } \\
\text { Variance partition } \mathrm{b}\end{array}$ & 260 & 4346.253 & 17.973 & & \\
$\quad \begin{array}{c}\text { Among groups } \\
\text { Among populations }\end{array}$ & 2 & 307.470 & 0.260 & 1.44 & $\mathrm{~F}_{\text {st }}=0.014$ \\
$\quad$ within groups & 3 & 326.298 & 3.215 & 17.83 & \\
within populations & 255 & 3712.486 & 14.559 & 80.73 & \\
$\quad$ Total & 260 & 4346.253 & 18.034 & & \\
\hline
\end{tabular}

${ }^{a}$ The first Bayesian clustering analyses (BCA) included all populations as one hierarchical group. ${ }^{\mathrm{b}}$ The second BCA included three geographical groups.

The geographic distances for all six wild populations were calculated using latitude and longitude, and ranged from $35.8 \mathrm{~km}$ to $190.6 \mathrm{~km}$. Genetic distance is estimated by pairwise $\mathrm{F}_{\mathrm{st}} /\left(1-\mathrm{F}_{\mathrm{st}}\right)$ among different populations, and then is regressed against the geographic distance. Mantel's test indicated that the correlations established using the reduced major axis regression for genetic distance value and the geographic distance were very weak among the five populations $\left(r^{2}=0.35, p=0.50\right)$. The greatest geographic distance was found between MJ and BMG, and the Rousset's distance between them was also the largest. Of the Rousset's distances, that between MJ and HZZ was the lowest. Thus, there was no significant correlation between genetic and geographic distances, which indicated that the geographic distances observed among populations were not key factors influencing genetic differentiation (Figure S3). 


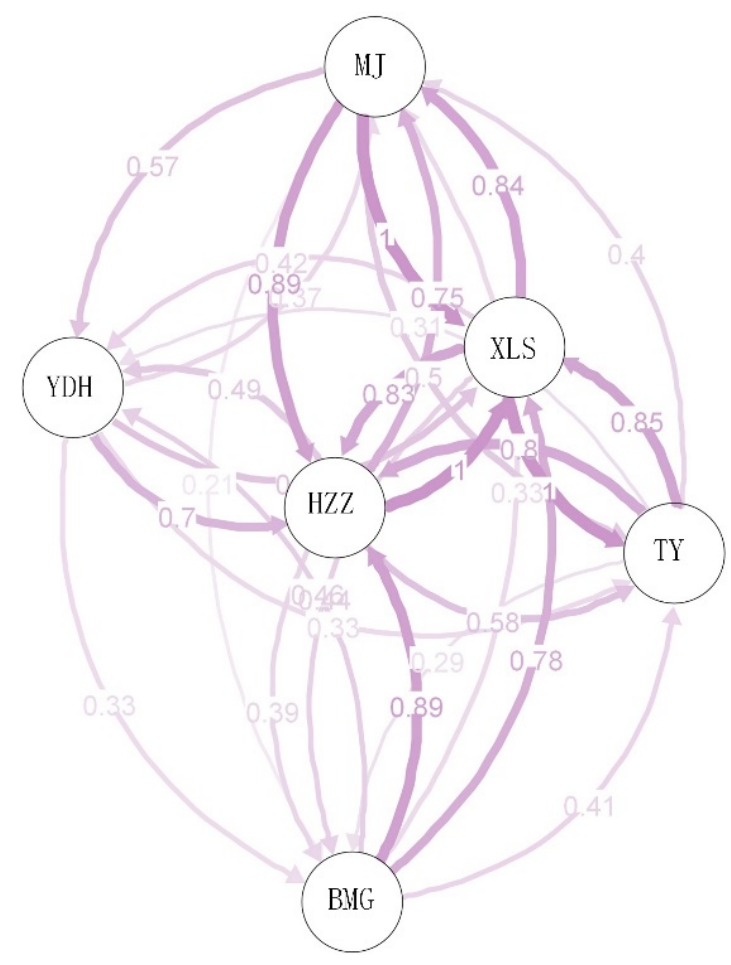

Figure 3. The relative migration networks of six populations from divMigrates. The width of the line and the number shown next to the arrows indicate the migration rate.

\subsection{Population Structure of A. miaotaiense}

An analysis of the structures of the six populations containing 261 individuals was performed with a Bayesian-based approach using the software STRUCTURE 2.3.4. The optimal number of clusters $(\mathrm{K})$ was identified based on the $\operatorname{LnP}(\mathrm{D})$ and posterior probability $(\Delta \mathrm{K})$ values. $\mathrm{K}$ was tested from one to eight with 10 repetitions performed for each run. In this study, a clear peak in the value of $\Delta \mathrm{K}$ was obtained at $\mathrm{K}=2$ (Figure $4 \mathrm{~b}, \mathrm{c}$ ). The tested $A$. miaotaiense individuals were grouped into two different clusters, $\mathrm{C} 1$ and $\mathrm{C} 2$ when $\mathrm{K}=2$ (Figures 1 and $4 \mathrm{a}$ ). $\mathrm{C} 1$ consisted of 149 individuals of one populations from the region G1 (XLS), C2 contained the remaining 112 individuals of five populations from the regions G2 (TY) and G3 (MJ, HZZ, YDH and BMG). In addition, 149 of 166 individuals collected from Gansu province were assigned into $C 1$, whereas the remaining 17 samples grouped into $C 2$. The admixture of the five populations (MJ, HZZ, YDH, BMG and TY) formed C2, and one population (XLS) formed the other cluster.

To further assess the populations' genetic structures, a PCA based on the 19 EST-SSR markers was used to generate a scatter plot of the six populations. The $261 \mathrm{~A}$. miaotaiense individuals were clearly separated into two broad groups across the first two axes (Figure $5 \mathrm{a}$ ). The first two principal coordinates explained $29.77 \%$ and $18.47 \%$, individually, and a combined $48.24 \%$ of the total variation, in which the first principal coordinate separated the XLS population. However, the MJ, HZZ, YDH, BMG and TY populations were mixed together, which further supported the STRUCTURE results, because MJ clustered with HZZ, YDH, BMG and TY. In addition, A. miaotaiense individuals originating in G2 and G3 were clustered in C2. Furthermore, a UPGMA tree of 261 individuals was constructed based on Nei's genetic distance (Figure 5b). Two major clusters clearly formed, and few individuals occurred as admixtures in different clusters. Populations containing 149, 17, 37, 29, 22 and 7 individuals are shown in blue, red, and green, yellow, light salmon and turquoise, respectively. These clustering results were consistent with the results of the PCA and model-based population structure analyses of the 261 A. miaotaiense individuals. 
a

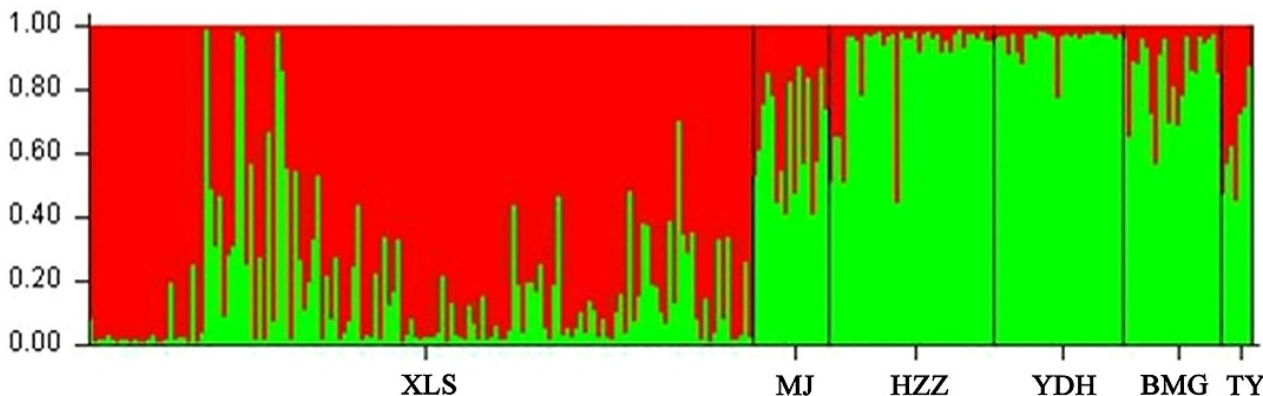

b

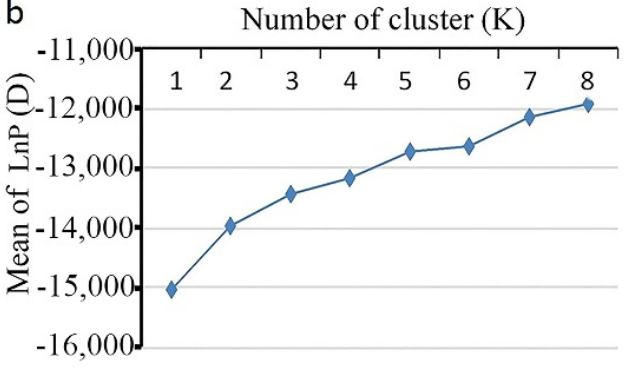

C

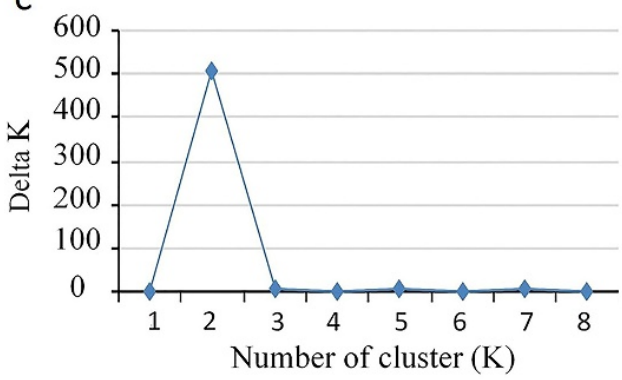

Figure 4. Population structure of 261 A. miaotaiense individuals based on 19 EST-SSRs markers. (a) Estimated genetic structure of the six populations based on STRUCTURE analysis; (b) Estimation of population using the mean of $\mathrm{Ln} P(\mathrm{D})$ based on ten repetitions for each $\mathrm{K}$ value; (c) plot of delta $\mathrm{K}(\Delta \mathrm{K})$ for $\mathrm{K}$ ranging from 1 to 8 .

a

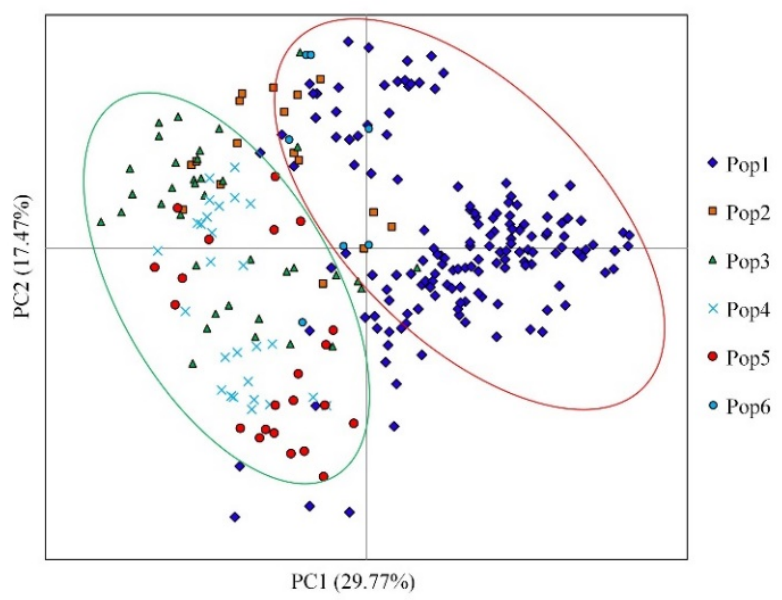

b

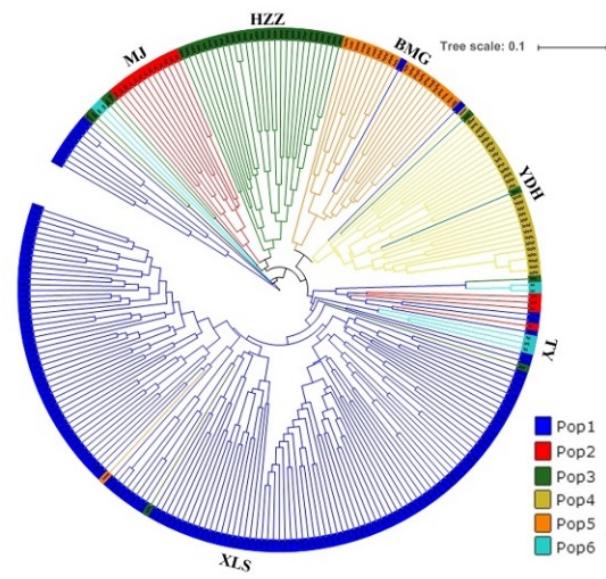

Figure 5. Graphical representation of differentiation between populations. (a) Principal component analyses (PCA). (b) UPGMA tree of 261 A. miaotaiense individuals.

\section{Discussion}

Genetic diversity is the result of the long-term evolution of species or populations $[48,49]$ and makes it possible to adapt to a changing environment. In particular, it is important to explore the causes and processes of rare or endangered species [50]. To design viable protection strategies for threatened species, a core requirement is the knowledge of genetic diversity and population structure. However, only limited publications reported on the development of molecular markers for the genetic analyses of $A$. miaotaiense [5]. Our study is the first attempt to obtain comprehensive transcriptional information for the development of EST-SSR markers and to further examine the diversity and genetic structure of extant natural A. miaotaiense populations. 
In total, $21,485,322$ high-quality clean reads were generated with $88.82 \%$ Q30 and a $44.46 \%$ GC content using Illumina paired-end sequencing, which was consistent with the results from transcriptome sequencing in P. dabeshanensis (44.58\%) [26] and Picrorhiza kurrooa (44.6\%) [51] but was higher than genus Gossypiumis (37\%) [52], Acer palmatum (44.33\%) [53] and Chlorophytum borivilianum (44\%) [54], indicating a better quality of sequencing. Furthermore, 93,305 unigenes were obtained from the sequence assembly, with an average length of $668 \mathrm{bp}$ and an N50 value of $1138 \mathrm{bp}$, which was longer than those reported-A. palmatum (average length $=564.78 \mathrm{bp}, \mathrm{N} 50=738 \mathrm{bp}$ ) [52] and Sepia esculenta (average length $=621 \mathrm{bp}, \mathrm{N} 50=911 \mathrm{bp}$ ) [55]—using the same technology, which might be attributable to the sequencing depth, assembly method and nature characteristics of the species. Thus, the transcriptome sequencing data of $A$. miaotaiense appeared to be of high quality and thus was utilized for further studies on marker development, population structure and genetic diversity. To understand the biological functions of assembled transcripts in A. miaotaiense, the functional annotations of the assembled unigenes were obtained using diverse public databases. For the GO analyses, 24,267 (45.32\%) unigenes were annotated into 41 GO terms and 'the cell part and cell', 'binding and catalytic activity' and 'cellular process and metabolic process' were the most abundant terms in the cellular component, molecular function and biological process categories, respectively, which was consistent with GO functional categories observed in Dipteronia oliver [31]. In addition, 19,473 (20.87\%) unigenes predicted by KEGG pathways were mapped to 131 biological pathways, and the majority of the categories were related to metabolism. The carbon metabolism (ko01200, 1185, $5.58 \%$ ) and biosynthesis of amino acids (ko01230, 858, 4.04\%) pathways were identified in this study. These results not only revealed the active metabolic processes in A. miaotaiense but also mean that multifarious metabolites are synthesized in this species. For $A$. miaotaiense and its related species, the leaves are the most important metabolic organ and contain large amounts of terpenoids, esters and aldehydes, which aid in resisting environmental and biological stresses, such as freezing, drought and pests. Moreover, some of unigenes were observed in plant hormone signal transduction (ko04075, $294,1.38 \%$ ) that responds to environmental information, such as abscisic, jasmonic and salicylic acids, which are related to stress. These results provide valuable functional annotation information for future investigations of gene function, stress responses and biological pathways in A. miaotaiense.

SSR markers have abundant types and are widely distributed in plant genomes [56]. In the present study, 12,765 potential EST-SSR molecular markers were identified from 93,305 unigenes, including 3049 unigenes that contained more than one EST-SSR locus, using RNA sequencing. The di-nucleotide repeats in EST-SSRs were the most abundant type in Michelia coriacea (Magnoliaceae) [57], Brassica oleracea [58], garlic [59] and Z. jujube [60]. In the identified 12,765 SSR markers of A. miaotaiense, the major repeat type was di-nucleotide $(2763,24.72 \%)$ after the removal of the mono-nucleotide repeats, which was consistent with previous findings, followed by tri-nucleotide repeats $(2362,21.13 \%)$. The most dominant di-nucleotide repeat motif of $A$. miaotaiense was AG/CT $(836,7.48 \%)$, which was consistent with studies in peanut [61] and D. oliver [31], but the most abundant tri-nucleotide repeat motif was different from those of other plants (GAA/TTC for A. miaotaiense, AAG/CTT for D. oliver and AAG/CTT for peanut). In particular, the CG/CG motif was not observed in A. miaotaiense, which further supports the conclusion that the CG/CG repeat is rare in many dicotyledonous plants [62-64].

Genetic diversity plays a significant role in the genetic improvement of germplasm resources, which has been widely applied in many plants [65-67]. The level of genetic diversity in a species is often related to the numbers of loci and populations [68], the size of the geographical range [69] and genetic exchange [70]. In the present study, there was still a high level of genetic diversity $\left(\mathrm{N}_{\mathrm{a}}=8\right.$, $\mathrm{H}_{\mathrm{o}}=0.528, \mathrm{H}_{\mathrm{e}}=0.635$ and PIC $\left.=0.604\right)$ in wild A. miaotaiense. These results are similar to those determined of seven wild populations of Acer davidii $\left(\mathrm{N}_{\mathrm{a}}=7.182, \mathrm{H}_{\mathrm{o}}=0.181\right.$ and $\left.\mathrm{H}_{\mathrm{e}}=0.389\right)$ as determined by using 11 primer pairs to evaluate the genetic diversity of SSR markers, He et al., 2017 [32]. However, a low level of genetic diversity has been found for the same family in D. oliver $\left(\mathrm{N}_{\mathrm{a}}=4.5, \mathrm{H}_{\mathrm{o}}=0.119\right.$ and $\left.\mathrm{H}_{\mathrm{e}}=0.714\right)$ [31] at the species level. The main reason for this difference is that only 44 individuals collected from six natural populations were used to analyze the genetic diversity 
in Zhou's study, whereas we collected 261 samples from six wild populations within the distribution range. Generally, species with small population sizes tend to maintain a low level of genetic diversity compared with widely spread species. However, there are contradictory conclusions [71]. In our study, A. miaotaiense is only naturally distributed in the Qinling Mountains, but its genetic diversity is higher than those of Oryza sativa $\left(\mathrm{N}_{\mathrm{a}}=4.8, \mathrm{H}_{\mathrm{o}}=0.07\right.$ and $\left.\mathrm{H}_{\mathrm{e}}=0.55\right)$ [72] and Phaseolus vulgaris $\left(\mathrm{N}_{\mathrm{a}}=2.7\right.$, $\mathrm{H}_{\mathrm{o}}=0.626$ and $\mathrm{H}_{\mathrm{e}}=0.308$ ) [73]. For other endangered species, such as M. coriacea (Magnoliaceae) [59], a restricted and fragmented distribution were determined in southeastern Yunnan Province, China, but a high level of genetic diversity and a low level of genetic differentiation were determined $\left(\mathrm{N}_{\mathrm{a}}=4.091\right.$, $\mathrm{H}_{\mathrm{e}}=0.505$ and $\mathrm{H}_{\mathrm{o}}=0.412$ for the SSR markers). Low levels of genetic diversity would not be beneficial in an expanded distribution region and could increase the possible susceptibility to diseases or insect pests. Thus, further studies on genetic protection should be used to construct a library of genetic diversity to preserve genetic variation within species. The distribution patterns of genetic structure are closely related to the breeding mechanisms and natural selection acting on species [74]. In this study, based on the different approaches (STRUCTURE, PCA and UPGMA), the 261 A. miaotaiense individuals were divided into two major distinct groups for the highest $\Delta \mathrm{K}$ value. However, each group was more or less mixed with the lineages of the other group, which was also reported in garlic [59].

Environmental conditions and species characteristics are also considered as critical factors and may affect genetic diversity. These have been shown in other plant species, such as Salix psammophila [66], Rhododendron jinggangshanicum [75] and Ranunculus acris [76]. In our field investigation, many abundant morphological variations were found firstly in A. miaotaiense, including shoulder-shaped leaves and flat fruit with three wings. Aditionally, it is perennial and wind-pollinated, which may be one cause of the high level of genetic diversity, the number of alleles, and the high PIC value among these samples. The genetic diversity varied in A. miaotaiense from different populations in China. XLS had the highest level of genetic diversity, while BMG had the lowest level of genetic diversity. The XLS is located in the western edge of the distribution area whereas BMG is located $1260 \mathrm{~m}$ at the southern edge of the Qinling Mountains. The marginal distribution may change allele frequency and generate a low level of genetic diversity. A. miaotaiense is mainly distributed in the Qinling Mountains ( $400-500 \mathrm{~km}$ from east to west, with an average altitude of more than $2000 \mathrm{~m}$ ) and is often used as an ornamental tree. A natural gene flow for $A$. miaotaiense over such a distance and altitude would be difficult, and one putative explanation may be frequent human actions. A. miaotaiense from different regions are often planted together, inducing gene flow and increasing diversity.

$\mathrm{F}_{\mathrm{st}}$ is an effective measure of genetic differentiation and gene flow between populations [77]. Moderate population differentiation (pairwise $\mathrm{F}_{\mathrm{st}}=0.059-0.116$ ) and weak population structure were found among the six natural populations. The greatest level of genetic differentiation was found between populations 2 and 5, and the distance between them was $\sim 187 \mathrm{~km}$, which indicated that long-term isolation may limit the level of gene flow between two populations. The same result was also shown in the relative migration networks of the six sampled populations. An AMOVA indicated that the greatest level of genetic differentiation in A. miaotaiense exists within populations $(81.01 \%)$, while less genetic differentiation occurs among the populations $(1.44 \%)$, and the same results have been reported in previous studies based on SSR markers $[78,79]$. It produced a high $\mathrm{F}_{\text {st }}$ value $(0.19>0.15)$, indicating great differentiation among populations [80]. This may be attributed to flower heterogeneity of Aceraceae species, smooth light pollen and anemophilous pollination with an outcrossing breeding system which could improve diversity within populations while reducing genetic diversity among the populations. The woody species with predominately outcrossing tend to have less differentiation among populations and high differentiation within populations [81]. The higher value of the within-population variance in this study is likely due to little gene flow between collection sites and specific mating systems from which the samples were derived.

Genetic differentiation into different populations is strongly influenced by gene flow, long-term evolution, genetic drift, selection and mutations [82]. In this study, the genetic differentiation within three geographical groups accounted for about $80.73 \%$ of the total, suggesting that there is less 
differentiation among them. A relatively high level of genetic diversity was found in the XLS population in A. miaotaiense, which inhabits relatively independent areas of Tianshui, Gansu Province, with relatively high number of $\mathrm{Na}$ and private alleles. Furthermore, the $\mathrm{F}_{\text {st }}$ value between XLS and other populations varied from $0.065-0.089$, indicating moderate levels of genetic differentiation. This variation difference may be explained by the larger sample size, adult trees and specific mating systems of XLS compared with other populations. The lowest $F_{\text {st }}$ value was detected in MJ and HZZ populations, suggesting a low degree of genetic differentiation between them, and this finding was consistent with the UPGMA analyses. It may be that the frequent human activity and geological history of the Qinling Mountains restricted the continuity of their distribution, but that the later development of a similar environment along ditch edges guided the evolution of the two populations in the same direction. The Nm value among A. miaotaiense populations ranged from 1.905 to 3.987, indicating the frequent flow of genes of populations. The clustering of $A$. miaotaiense populations showed a clear separation according to the dendrogram from Nei's genetic distance matrix by UPGMA. In terms of population structure, the populations from G2 and G3 were nearly clustered into C2, while the populations from G1 were clustered into C1, except MJ, which is not consist with the known geographical location information (G1, G2 and G3). Similar results were also found using Mantel's test for the correlation between genetic distance value and the geographic distance matrix $\left(r^{2}=0.35\right.$, $p=0.50$ ). These results showed that the genetic distance was not significantly correlated with the geographic distance, suggesting that geographic distance is not the principal factor influencing genetic differentiation in A. miaotaiense.

Maintenance of high genetic diversity and a reasonable population structure are the core goals for the conservation of the endangered species and are of great significance in the establishment of conservation policies and scientific measures. Only few adult fruiting trees were observed in the sampled regions, among which XLS populations had a relatively greater number of adult trees with only 46 individuals. Natural regeneration is difficult and there are very few young seedlings in the forest. Thus, an effective policy should first protect the habitat and natural populations, especially populations with higher levels of genetic diversity (XLS and HZZ), and take some measures for in situ conservation, such as the establishment of natural protective areas to shelter as many individuals as possible. The greatest level of genetic differentiation was found between the MJ and BMG populations. To protect independent population units, these populations are the most important for in situ conservation to maintain as much genetic diversity as possible. Furthermore, overexploitation may be the main cause for the reduction in population sizes according to the field survey. Therefore, necessary protective policies, laws and regulations must be instituted by the government to forbid the unlawful felling and exploitation of this endangered species' environment. To avoid further losses in population size, all of these extant populations (XLS, MJ, HZZ, YDH, BMG and TY) should be protected.

In addition, impactful ex situ conservation approaches are of great importance for maintaining A. miaotaiense' natural genetic resources. Because of the current habitat loss and low seed-setting rate, the TY population only contains seven individuals, including two adult trees, and its genetic diversity level was the lowest. The principal protection of the TY population should involve ex situ conservation to rescue the remaining individuals. XLS contains the greatest number of individuals and has the highest genetic diversity level; therefore, a seed bank and resource nursery should be established through breeding experiments and transplantation. Moreover, samples from the entire natural distribution range should also be collected in botanical gardens with suitable habitats to increase the chances of gene flow among populations. To summarize, a high genetic diversity level was observed in A. miaotaiense, but its distribution was narrow. Therefore, comprehensive protective measures should be taken along with in situ or ex situ conservation. In particular, we should attach great importance to the protection of extant $A$. miaotaiense populations and seriously implement protective strategies to maintain the high level of genetic diversity. 
Supplementary Materials: The following are available online at http://www.mdpi.com/2073-4425/9/8/378/s1, Figure S1: Eukaryotic orthologous groups (KOG) classification of Acer miaotaiense unigenes, Figure S2: Distribution of the top BLASTX hits for the unigenes in the NCBI non-redundant protein (Nr) database, Figure S3: RMA regression of genetic distance and geographic distance $(\mathrm{Km})$ matrix of Acer miaotaiense $\left(r^{2}=0.35, p=0.50\right)$, Table S1: Summary of the analysis of de novo assembled of Acer miaotaiense, Table S2: Summary Analyses of transcriptome sequencing for A. miaotaiense, Table S3: The Kyoto Encyclopedia of Genes and Genomes (KEGG) annotation, Table S4: Summary of the Analyses of EST-SSRs for A. miaotaiense, Table S5: The number of repeats in each different motif length in the Acer miaotaiense, Table S6: Frequencies of different repeat motifs in SSRs in Acer miaotaiense, Table S7: The list of 96 SSRs with stable amplification, Table S8: The gene flow value among the six populations in Acer miaotaiense.

Author Contributions: Y.L. designed the idea and experiments; X.L. performed the experiments; X.L. and L.H. collected and analyzed the data; X.L. wrote the manuscript; X.P., L.H., M.L. and Z.Z. provided useful suggestions on the manuscript; X.P., M.L. and Y.L. revised the manuscript; Y.L. obtained funding and is responsible for this article. All authors read and approved the final manuscript.

Funding: This research study was supported by the Fundamental Research Funds for the Central Universities (No. 2017ZY24), the Project of the Field Ambulance and Breeding of Rare and Endangered Species of the State Forestry Administration (No. 20170501), and the Major Science and Technology Special Project of Xuchang, Henan Province (No. 20170112006).

Conflicts of Interest: The authors declare no conflict of interest.

\section{References}

1. Cao, X.Y.; Chen, K. Studies on the reproductive biology of a China rare plant-Acer miaotaiense1. Morphology and development of inflorescence and flower. Acta Bot. Boreali Occident. Sin. 1997, 5, 107-111.

2. Zhang, Y.; Li, B.; Chen, H.; Wang, Y.C. Characterization of the complete chloroplast genome of Acer miaotaiense (Sapindales: Aceraceae), a rare and vulnerable tree species endemic to China. Conserv. Genet. Resour. 2016, 8, 1-3. [CrossRef]

3. Fu, L.G. China Plant Red Data Book; Science Press: Beijing, China, 1992; pp. 107-108.

4. International Union for Conservation of Nature and Natural Resources. Available online: http://dx.doi.org/ 10.2305/IUCN.UK.2004.RLTS.T46387A11048479.en (accessed on 12 June 2018).

5. Shan, L.I.; Yan, G.Q.; Zhao, G.F. Population genetic structure and genetic diversity of Acer miaotaiense. J. Northwest Univ. 2005, 35, 71-75.

6. Meng, Q.F.; Gao, H.L.; Li, H.X.; Xu, H.J. Biological and ecological characteristics of rare and endangered species of Acer miaotaiense. Henan Sci. 2016, 11, 1830-1834.

7. Meng, Q.F.; Gao, H.L.; Wang, H.Y. Fruiting characteristics and sowing seedlings of rare and endangered species of Acer miaotaiense. Henan Sci. 2017, 11, 1773-1777.

8. Wei, D.L. Study on sowing and seedling rising of rare species of Acer miaotaiense. J. Gansu For. Sci. Technol. 2017, 2, 37-39.

9. Lu, Z.R. Rare and endangered species of Acer miaotaiense investigation and analysis in Xiaolongshan forest population distribution. Jilin Agric. 2011, 2, 165-166.

10. Lei, S.G.; Ma, J.W.; Zhang, S.Z.; Hu, W.B.; Guo, X.L.; Du, Y.C.; Li, A.M. Preliminary research on community structure of Acer miaotaiense in the Xiaolongshan forest area. J. Gansu For. Sci. Technol. 2009, 34, 1-5.

11. Wang, H.; Pan, G.; Ma, Q.; Zhang, J.; Pei, D. The genetic diversity and introgression of Juglans regia and Juglans sigillata in Tibet as revealed by SSR markers. Tree Genet. Genome 2015, 11, 1. [CrossRef]

12. Wang, Q.; Zhang, L.; Zheng, P. Genetic diversity and evolutionary relationship analyses within and among Raphanus species using EST-SSR markers. Mol. Breed. 2015, 35, 62. [CrossRef]

13. Deng, T.X.; Pang, C.Y.; Lu, X.R.; Zhu, P.; Duan, A.Q.; Tan, Z.Z.; Huang, J.; Li, H.; Chen, M.T.; Liang, X.W. De novo transcriptome assembly of the Chinese swamp buffalo by RNA sequencing and SSR marker discovery. PLoS ONE 2016, 11, e0147132. [CrossRef] [PubMed]

14. Khan, M.K.R.; Chen, H.D.; Zhou, Z.L.; Ilyas, M.K.; Wang, X.X.; Cai, X.Y.; Wang, C.Y.; Liu, F.; Wang, K.B. Genome wide SSR high density genetic map construction from an interspecific cross of Gossypium hirsutum $\times$ Gossypium tomentosum. Front. Plant Sci. 2016, 7, 436. [CrossRef] [PubMed]

15. Liang, W.; Dondini, L.; Franceschi, P.D.; Paris, R.; Sansavini, S.; Tartarini, S. Genetic diversity, population structure and construction of a core collection of apple cultivars from Italian germplasm. Plant Mol. Biol. Rep. 2015, 33, 458-473. [CrossRef] 
16. Cheng, J.W.; Zhao, Z.Z.; Bo, L.; Cheng, Q.; Wu, Z.M.; Trejosaavedra, D.L.; Luo, X.R.; Cui, J.J.; Riverabustamante, R.F.; Li, S.C. A comprehensive characterization of simple sequence repeats in pepper genomes provides valuable resources for marker development in Capsicum. Sci. Rep. 2016, 6, 18919. [CrossRef] [PubMed]

17. Aboukhalid, K.; Machon, N.; Lambourdière, J.; Abdelkrim, J.; Bakha, M.; Douaik, A.; Korbecka-Glinka, G.; Gaboun, F.; Gaboun, F.; Lamiri, A. Analyses of genetic diversity and population structure of the endangered Origanum compactum from Morocco, using SSR markers: Implication for conservation. Biol. Conserv. 2017, 212, 172-182. [CrossRef]

18. Yang, H.; Li, X.; Liu, D.; Chen, X.; Li, F.; Qi, X.L. Genetic diversity and population structure of the endangered medicinal plant Phellodendron amurense in China revealed by SSR markers. Biochem. Syst. Ecol. 2016, 66, 286-292. [CrossRef]

19. Lopez, L.; Barreiro, R. Genetic guidelines for the conservation of the endangered polyploid Centaurea borjae (Asteraceae). J. Plant Res. 2013, 126, 81-93. [CrossRef] [PubMed]

20. Zhou, X.J.; Wang, Y.Y.; Xu, Y.N.; Yan, R.S.; Zhao, P.; Liu, W.Z. De novo characterization of flower bud transcriptomes and the development of EST-SSR markers for the endangered tree Tapiscia sinensis. Int. J. Mol. Sci. 2015, 16, 12855-12870. [CrossRef] [PubMed]

21. Irizarry, K.J.L.; Bryant, D.; Kalish, J.; Eng, C.; Schmidt, P.L.; Barrett, G.; Margaret, C.B. Integrating genomic data sets for knowledge discovery: An informed approach to management of captive endangered species. Int. J. Genom. 2016, 2, 1-12. [CrossRef] [PubMed]

22. Zhang, Y.Y.; Shi, E.; Yang, Z.P.; Geng, Q.F.; Qiu, Y.X.; Wang, Z.S. Development and application of genomic resources in an endangered palaeoendemic tree, Parrotia subaequalis (Hamamelidaceae) from Eastern China. Front. Plant Sci 2018, 9, 246. [CrossRef] [PubMed]

23. Peterson, M.P.; Whittaker, D.J.; Ambreth, S.; Sureshchandra, S.; Buechlein, A.; Podicheti, R.; Choi, J.H.; Lai, Z.; Mockatis, K.; Cilbourne, J.; et al. De novo transcriptome sequencing in a songbird, the dark-eyed junco (Junco hyemalis): Genomic tools for an ecological model system. BMC Genom. 2012, 13, 305. [CrossRef] [PubMed]

24. Chen, L.Y.; Cao, Y.N.; Yuan, N.; Nakamura, K.; Wang, G.M.; Qiu, Y.X. Characterization of transcriptome and development of novel EST-SSR makers based on next-generation sequencing technology in Neolitsea sericea (Lauraceae) endemic to East Asian land-bridge islands. Mol. Breed. 2015, 35, 187. [CrossRef]

25. Shiferaw, E.; Pè, M.E.; Porceddu, E.; Ponnaiah, M. Exploring the genetic diversity of Ethiopian grass pea (Lathyrus sativus L.) using EST-SSR markers. Mol. Breed. 2012, 30, 789-797. [CrossRef] [PubMed]

26. Xiang, X.Y.; Zhang, Z.X.; Wang, Z.G.; Zhang, X.P.; Wu, G.L. Transcriptome sequencing and development of EST-SSR markers in Pinus dabeshanensis, an endangered conifer endemic to China. Mol. Breed. 2015, 35, 158. [CrossRef]

27. Liu, J.; Liu, H.B.; Ma, L.Y.; Wang, S.Q.; Gao, J.; Li, Y.Y.; Wu, R.L.; Pang, X.M. A Chinese jujube (Ziziphus jujuba Mill.) fruit-expressed sequence tag (EST) library: Annotation and EST-SSR characterization. Sci. Hortic. 2014, 165, 99-105. [CrossRef]

28. Wu, J.; Cai, C.F.; Cheng, F.Y.; Cui, H.L.; Zhou, H. Characterisation and development of EST-SSR markers in tree peony using transcriptome sequences. Mol. Breed. 2014, 34, 1853-1866. [CrossRef]

29. Guo, Q.; Wang, J.X.; Su, L.Z.; Lv, W.; Sun, Y.H.; Li, Y. Development and evaluation of a novel set of EST-SSR markers based on transcriptome sequences of black locust (Robinia pseudoacacia L.). Genes 2017, 8, 177. [CrossRef] [PubMed]

30. Sun, Q.M.; Bai, L.J.; Ke, L.X.; Xiang, X.; Zhao, J.S.; Ou, L.X. Developing a core collection of litchi (Litchi chinensis Sonn.) based on EST-SSR genotype data and agronomic traits. Sci. Hortic. 2012, 146, 29-38. [CrossRef]

31. Zhou, T.; Li, Z.H.; Bai, G.Q.; Feng, L.; Chen, C.; Wei, Y.; Chang, Y.X.; Zhao, G.F. Transcriptome sequencing and development of genic SSR markers of an endangered Chinese endemic genus Dipteronia Oliver (Aceraceae). Molecules 2016, 21, 166. [CrossRef] [PubMed]

32. He, Y.L.; He, Y.; Gong, L.L.; Fang, M.F.; Li, Z.H. Population genetic structure and interspecific differentiation between Acer davidii, Franchi. and A. morrisonense, Hayata (Aceraceae) based on SSR markers. Biochem. Syst. Ecol. 2017, 71, 42-49. [CrossRef] 
33. Ghawana, S.; Paul, A.; Kumar, H.; Kumar, A.; Singh, H.; Bhardwaj, P.K.; Rani, A.; Singh, R.S.; Raizada, J.; Singh, K. An RNA isolation system for plant tissues rich in secondary metabolites. BMC Res. Notes 2011, 4, 85. [CrossRef] [PubMed]

34. Grabherr, M.G.; Haas, B.J.; Yassour, M.; Levin, J.Z.; Thompson, D.A.; Amit, I.; Xian, A.; Fan, L.; Raychowdhury, R.; Zeng, Q.D. Trinity: Reconstructing a full-length transcriptome without a genome from RNA-Seq data. Nat. Biotechnol. 2011, 29, 644. [CrossRef] [PubMed]

35. Conesa, A.; Götz, S.; Garcíagómez, J.M.; Teroi, J.; Terol, J.; Talón, M.; Robles, M. Blast2GO: A universal tool for annotation, visualization and analysis in functional genomics research. Bioinformatics 2005, 21, 3674-3676. [CrossRef] [PubMed]

36. Zhang, Z.Y.; Cui, B.B.; Mao, J.F.; Pang, X.M.; Liu, H.; Li, Y.Y. Novel polymorphic EST-derived microsatellite markers for the red-listed five needle pine, Pinus dabeshanensis. Conserv. Genet. Resour. 2015, 7, $191-192$. [CrossRef]

37. Mitchell, M.; Walther, P. GeneMarker ${ }^{\circledR}$ HID: A Reliable Software Tool for the Analyses of Forensic STR Data. J. Forensic Sci. 2011, 56, 29-35.

38. Peakall, R.; Smouse, P.E. GenAlEx 6.5: Genetic analysis in Excel. Population genetic software for teaching and research-An update. Bioinformatics 2012, 28, 2537-2539. [CrossRef] [PubMed]

39. Nagy, S.; Poczai, P.; Cernák, I.; Gorji, A.M.; Hegedús, G.; Taller, J. PICcalc: An online program to calculate polymorphic information content for molecular genetic studies. Biochem. Genet. 2012, 50, 670-672. [CrossRef] [PubMed]

40. Falush, D.; Stephens, M.; Pritchard, J.K. Inference of population structure using multilocus genotype data: Linked loci and correlated allele frequencies. Genetics 2003, 164, 1567-1587. [PubMed]

41. Earl, D.A.; Vonholdt, B.M. STRUCTURE HARVESTER: A website and program for visualizing STRUCTURE output and implementing the Evanno method. Conserv. Genet. Resour. 2012, 4, 359-361. [CrossRef]

42. Nei, M.F.; Tajima, F.; Tateno, Y. Accuracy of estimated phylogenetic trees from molecular data. II. Gene frequency data. J. Mol. Evol. 1983, 19, 153-170. [CrossRef] [PubMed]

43. Liu, K.; Muse, S.V. PowerMarker: An integrated analyses environment for genetic marker analyses. Bioinformatics 2005, 21, 2128-2129. [CrossRef] [PubMed]

44. Letunic, I.; Bork, P. Interactive Tree Of Life (iTOL): An online tool for phylogenetic tree display and annotation. Bioinformatics 2007, 23, 127-128. Available online: http:/ /itol.embl.de/ (accessed on 15 July 2018). [CrossRef] [PubMed]

45. Sundqvist, L.; Keenan, K.; Zackrisson, M.; Prodöhl, P.; Kleinhans, D. Directional genetic differentiation and relative migration. Ecol. Evol. 2016, 6, 3461-3475. [CrossRef] [PubMed]

46. Keenan, K.; Mcginnity, P.; Cross, T.F.; Crozier, W.W.; Prodöhl, P.A. Diversity: An R package for the estimation and exploration of population genetics parameters and their associated errors. Methods Ecol. Evol. 2013, 4, 782-788. [CrossRef]

47. Ihaka, R.; Gentleman, R. R: A Language for Data Analyses and Graphics. J. Comput. Graph. Stat. 1996, 5, 299-314.

48. Masmoudi, M.B.; Chaoui, L.; Topçu, N.E.; Hammami, P.; Kara, M.H.; Aurelle, D. Contrasted levels of genetic diversity in a benthic Mediterranean octocoral: Consequences of different demographic histories? Ecol. Evol. 2016, 6, 8665-8678. [CrossRef] [PubMed]

49. Senczuk, G.; Colangelo, P.; Simone, E.D.; Aloise, G.; Castiglia, R. A combination of long term fragmentation and glacial persistence drove the evolutionary history of the Italian wall lizard Podarcis siculus. BMC Evol. Biol. 2017, 17, 6. [CrossRef] [PubMed]

50. Donnell, C.F.J.O.; Richter, S.; Dool, S.; Monks, J.M.; Kerth, G. Genetic diversity is maintained in the endangered New Zealand long-tailed bat (Chalinolobus tuberculatus) despite a closed social structure and regular population crashes. Conserv. Genet. 2016, 17, 91-102. [CrossRef]

51. Parul, G.; Heikham, R.S.; Ravi, S.; Niharika, S.; Anita, K.; Vandna, C.; Paramvir, S.A.; Sanjay, K. De novo sequencing and characterization of Picrorhiza kurrooa transcriptome at two temperatures showed major transcriptome adjustments. BMC Genom. 2012, 13, 126.

52. Tao, T.; Zhao, L.; Lv, Y.D.; Chen, J.D.; Hu, Y.; Zhang, T.Z.; Zhou, B.L. Transcriptome sequencing and differential gene expression analyses of delayed gland morphogenesis in Gossypium australe during seed germination. PLoS ONE 2013, 8, e75323. [CrossRef] [PubMed] 
53. Rong, L.; Li, Q.; Li, S.; Tang, L.; Wen, J. De novo transcriptome sequencing of Acer palmatum and comprehensive analyses of differentially expressed genes under salt stress in two contrasting genotypes. Mol. Genet. Genom. 2016, 291, 575-586. [CrossRef] [PubMed]

54. Kalra, S.; Puniya, B.L.; Kulshreshtha, D.; Kumar, S.; Kaur, J.; Ramachandran, S.; Singh, K. De novo transcriptome sequencing reveals important molecular networks and metabolic pathways of the plant, Chlorophytum borivilianum. PLoS ONE 2013, 8, e83336. [CrossRef] [PubMed]

55. Liu, C.L.; Zhao, F.; Yan, J.Z.; Liu, C.S.; Liu, S.W.; Chen, S.Q. Transcriptome sequencing and de novo assembly of golden cuttlefish Sepia esculenta Hoyle. Int. J. Mol. Sci. 2016, 17, 1749. [CrossRef] [PubMed]

56. Huang, L.; Wu, B.; Zhao, J.; Li, H.; Chen, W.; Zheng, Y.; Ren, X.; Chen, Y.; Zhou, X.; Lei, Y.; et al. Characterization and transferable utility of microsatellite markers in the wild and cultivated Arachis species. PLoS ONE 2016, 11, e0156633. [CrossRef] [PubMed]

57. Zhao, X.; Ma, Y.; Sun, W.; Wen, X.; Milne, R. High genetic diversity and low differentiation of Michelia coriacea (Magnoliaceae), a critically endangered endemic in Southeast Yunnan, China. Int. J. Mol. Sci. 2012, $13,4396$. [CrossRef] [PubMed]

58. Li, H.; Chen, X.; Yang, Y.; Xu, J.; Gu, J.; Fu, J.; Qian, X.; Zhang, S.; Wu, J.; Liu, K. Development and genetic mapping of microsatellite markers from whole genome shotgun sequences in Brassica oleracea. Mol. Breed. 2011, 28, 585-596. [CrossRef]

59. Ipek, M.; Sahin, N.; Ipek, A.; Cansev, A.; Simon, P.W. Development and validation of new SSR markers from expressed regions in the garlic genome. Sci. Agric. 2015, 72, 41-46. [CrossRef]

60. Ma, Q.Y.; Dai, X.G.; Chen, Y.N.; Zhang, D.F.; Liao, Z.Y.; Li, S.X. Characterization of microsatellites in the genome of Ziziphus jujuba. Sci. Silvae Sin. 2013, 12, 81-87.

61. Zhong, R.C.; Zhou, M.L.; Zhao, C.Z.; Hou, L.; Li, C.S.; Wang, X.J.; Tang, R.H.; Xia, H. SSR marker development from peanut gynophore transcriptome sequencing. Plant Breed. 2016, 135, 111-117. [CrossRef]

62. Kumpatla, S.P.; Mukhopadhyay, S. Mining and survey of simple sequence repeats in expressed sequence tags of dicotyledonous species. Genome 2005, 48, 985-998. [CrossRef] [PubMed]

63. Huang, D.N.; Zhang, Y.Q.; Jin, M.D.; Li, H.K.; Song, Z.P.; Wang, Y.G.; Chen, J. Characterization and high cross-species transferability of microsatellite markers from the floral transcriptome of Aspidistra saxicola (Asparagaceae). Mol. Ecol. Resour. 2014, 14, 569-577. [CrossRef] [PubMed]

64. Yue, X.Y.; Liu, G.Q.; Zong, Y.; Teng, Y.W.; Cai, D.Y. Development of genic SSR markers from transcriptome sequencing of pear buds. J. Zhejiang Univ. Sci. 2014, 15, 303-312. [CrossRef] [PubMed]

65. Chen, T.; Huang, X.J.; Zhang, J.; Chen, Q.; Liu, Y.; Tang, H.R.; Pan, D.M.; Wang, X.R. Genetic diversity and population structure patterns in Chinese Cherry (Prunus pseudocerasus, Lindl) Landraces. Plant Mol. Biol. Rep. 2015, 34, 1-14. [CrossRef]

66. Jia, H.; Yang, H.; Sun, P.; Li, J.; Zhang, J.; Guo, Y.; Han, X.; Zhang, G.; Lu, M.; Hu, J. De novo transcriptome assembly, development of EST-SSR markers and population genetic analyses for the desert biomass willow, Salix psammophila. Sci. Rep. 2016, 6, 39591. [CrossRef] [PubMed]

67. Mi, Y.C.; López-Pujol, J.; Son, S.; Suh, G.U.; Yukawa, T.; Chung, M.G. Patterns of genetic diversity in rare and common orchids focusing on the Korean peninsula: Implications for conservation. Bot. Rev. 2018, 84, 1-25.

68. Ferrer, M.M.; Eguiarte, L.E.; Montaña, C. Genetic structure and outcrossing rates in Flourensia cernua (Asteraceae) growing at different densities in the South-Western Chihuahuan Desert. Ann. Bot. 2004, 94, 419-426. [CrossRef] [PubMed]

69. Li, J.H.; Jin, Z.X.; Lou, W.Y.; Li, J.M. Genetic diversity of Lithocarpus harlandii populations in three forest communities with different succession stages. Chin. J. Ecol. 2008, 3, 106-111. [CrossRef]

70. Hellmann, J.J.; Pineda-Krch, M. Constraints and reinforcement on adaptation under climate change: Selection of genetically correlated traits. Biol. Conserv. 2007, 140, 599-609. [CrossRef]

71. Yang, Z.Y.; Yi, T.S.; Zeng, L.Q.; Gong, X. The population genetic structure and diversification of Aristolochia delavayi (Aristolochiaceae), an endangered species of the dry hot valleys of the Jinsha River, Southwestern China. Botany 2014, 92, 579-587. [CrossRef]

72. Babu, B.K.; Meena, V.; Agarwal, V.; Agrawal, P.K. Population structure and genetic diversity analyses of Indian and exotic rice (Oryza sativa L.) accessions using SSR markers. Mol. Biol. Rep. 2014, 41, 4329-4339. [CrossRef] [PubMed] 
73. Xu, S.C.; Wang, G.F.; Mao, W.H.; Hu, Q.Z.; Liu, N.; Ye, L.W.; Gong, Y.M. Genetic diversity and population structure of common bean (Phaseolus vulgaris) landraces from China revealed by a new set of EST-SSR markers. Biochem. Syst. Ecol. 2014, 57, 250-256. [CrossRef]

74. Zhang, P.; Li, J.Q.; Li, X.L.; Liu, X.D.; Zhao, X.J.; Lu, Y.G. Population structure and genetic diversity in a rice core collection (Oryza sativa L.) investigated with SSR markers. PLoS ONE 2011, 6, e27565. [CrossRef] [PubMed]

75. Li, M.; Chen, S.; Shi, S.; Zhang, Z.; Liao, W.B.; Wu, W.; Zhou, R.C.; Fan, Q. High genetic diversity and weak population structure of Rhododendron jinggangshanicum, a threatened endemic species in Mount Jinggangshan of China. Biochem. Syst. Ecol. 2015, 58, 178-186. [CrossRef]

76. Odat, N.; Jetschke, G.; Hellwig, F.H. Genetic diversity of Ranunculus acris L. (Ranunculaceae) populations in relation to species diversity and habitat type in grassland communities. Mol. Ecol. 2004, 13, 1251-1257. [CrossRef] [PubMed]

77. Peng, L.P.; Cai, C.F.; Zhong, Y.; Xu, X.X.; Xian, H.L.; Cheng, F.Y.; Mao, J.F. Genetic analyses reveal independent domestication origins of the emerging oil crop Paeonia ostii, a tree peony with a long-term cultivation history. Sci. Rep. 2017, 7, 5340. [CrossRef] [PubMed]

78. Wang, Z.; Kang, M.; Liu, H.; Gao, J.; Zhang, Z.; Li, Y.; Wu, R.; Pang, X. High-level genetic diversity and complex population structure of Siberian apricot (Prunus sibirica L.) in China as revealed by nuclear SSR markers. PLoS ONE 2014, 9, e87381. [CrossRef] [PubMed]

79. Sun, R.X.; Lin, F.R.; Huang, P.; Zheng, Y.Q. Moderate genetic diversity and genetic differentiation in the relict tree Liquidambar formosana Hance revealed by genic simple sequence repeat markers. Front. Plant Sci. 2016, 7, 1411. [CrossRef] [PubMed]

80. Hamrick, J.L.; Godt, M.J.W. Effects of life history traits on genetic diversity in plant species. Philos. Trans. Biol. Sci. 1996, 351, 1291-1298. [CrossRef]

81. Wright, S. Evolution and the Genetics of Population, Variability within and among Natural Populations; The University of Chicago Press: Chicago, IL, USA, 1978.

82. Schaal, B.A.; Hayworth, D.A.; Olsen, K.M.; Rauscher, J.T.; Smith, W.A. Phylogeographic studies in plants: Problems and prospects. Mol. Ecol. 1998, 7, 465-474. [CrossRef]

(C) 2018 by the authors. Licensee MDPI, Basel, Switzerland. This article is an open access article distributed under the terms and conditions of the Creative Commons Attribution (CC BY) license (http:/ / creativecommons.org/licenses/by/4.0/). 